\title{
Current perspectives on the home and outpatient use of parenteral antibiotics in Canada: An overview of the conference
}

\author{
H Grant Stiver MD FRCPC
}

$\mathrm{S}$ ince the initial clinical trial demonstrating the safety, efficacy and cost advantages of outpatient intravenous antibiotic therapy (OPAT) in the mid-1970s, outpatient parenteral antibiotic therapy has become a major therapeutic program in most Canadian hospitals (1). In the mid-1990s, the value of this avenue of treatment had become even more apparent as greater cutbacks in the availability of hospital care take place. Because many patients requiring three to four weeks of antibiotic therapy now routinely receive two-thirds of the course at home or at an infusion clinic, the average cost ratio comparing OPAT with hospital-based therapy is 12 cents on the dol$\operatorname{lar}(2)$.

The degree of patient and patient's family satisfaction has been high, and newer infusion devices (eg, peripherally inserted catheters) and computerized ambulatory drug delivery pumps allow almost any type of antibiotic regimen to be given with a minimum of intervention required from the patient (3).

OPAT has always been a team concept comprising usually, but not necessarily, infectious disease physicians, clinical pharmacists and nursing specialists. The OPAT conference held in Toronto, April 17 to 19, 1998, brought together experi- enced health care personnel from across Canada to compare different provincial OPAT programs regarding methods of funding, logistical approaches, pharmacological and therapeutic profiles, clinical experiences, and future plans. In addition, a major focus of the conference was to formulate clinical care plans for the antibiotic management of endocarditis, septic arthritis and osteomyelitis, diabetic foot infection, respiratory tract infection, cellulitis and infection in neutropenic patients, and to provide definitions of the role of OPAT in these infections. It is hoped that physicians and other OPAT healthcare personnel in the community will be able to use these care plans, and OPAT therapeutic and care overviews as guidelines for OPAT in their own practice settings.

\section{REFERENCES}

1. Stiver HG, Telford GO, Mossey JM, et al. Intravenous antibiotic therapy at home. Ann Intern Med 1978;89:690-3.

2. Wai A, Jewesson PJ. Department of Pharmaceutical Sciences, Vancouver Hospital and Health Sciences Centre, update data, Outpatient Intravenous Antibiotic Program. June, 1998.

3. Tice AD. Handbook of Outpatient Parenteral Therapy of Infectious Diseases. New York: Scientific American Inc, 1997:75-82. 


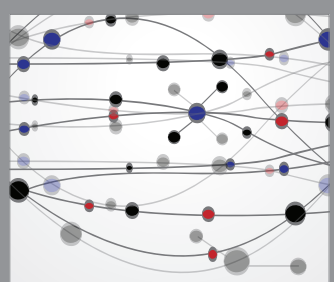

The Scientific World Journal
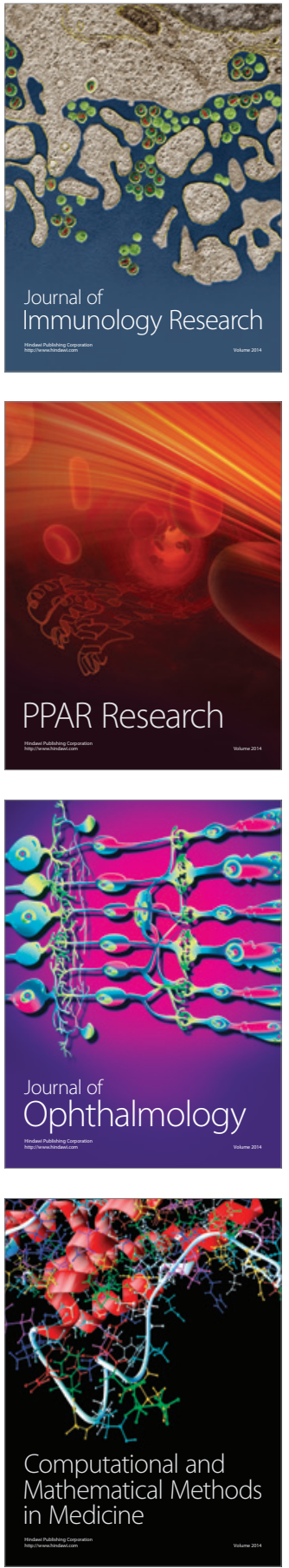

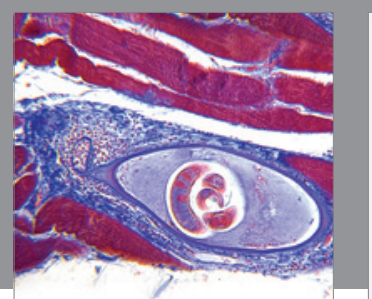

Gastroenterology Research and Practice

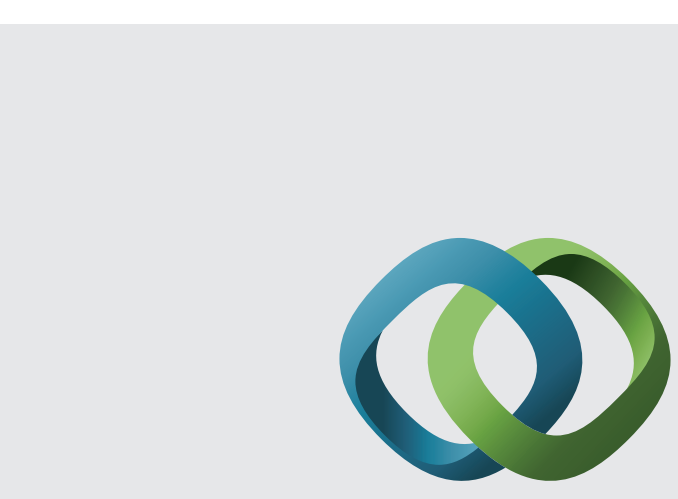

\section{Hindawi}

Submit your manuscripts at

http://www.hindawi.com
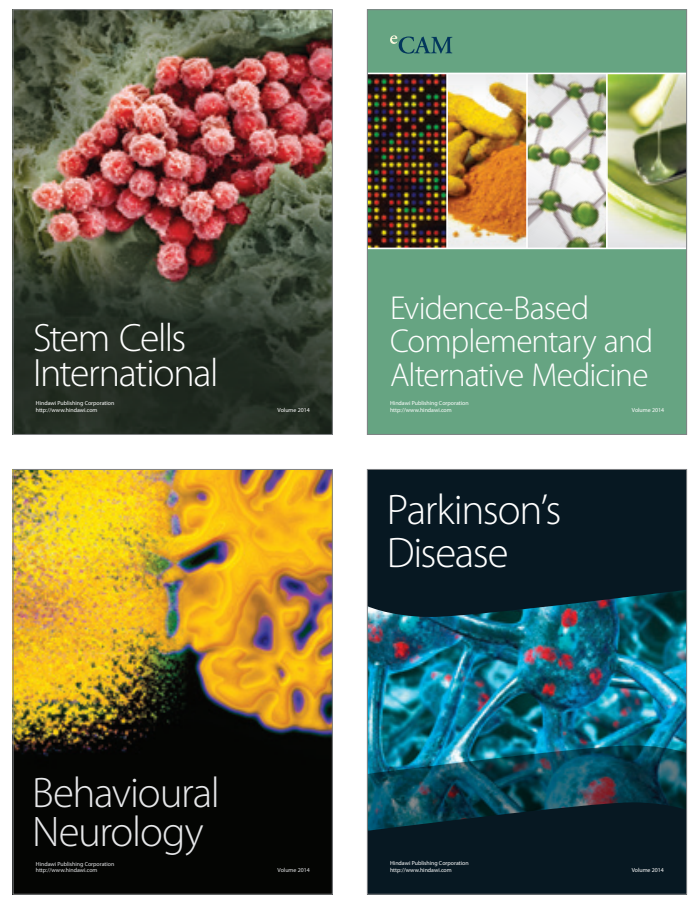
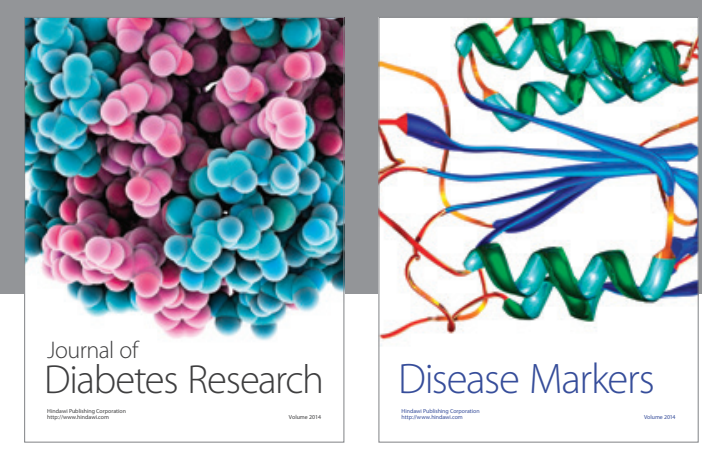

Disease Markers
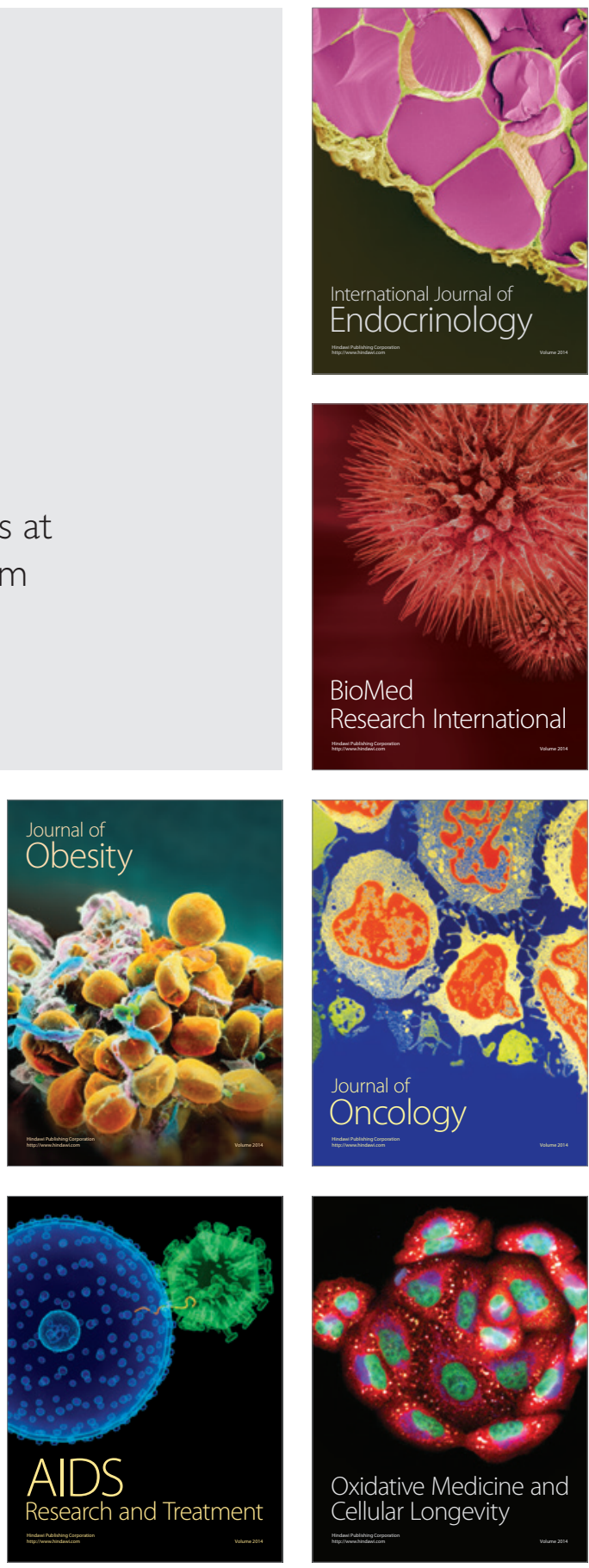